\title{
Removal of Dyes Form Textile Wastewater by Adsorption using Shrimp Shell
}

\section{Rahman FBA* and Akter M}

School of Environmental Science and Management, Independent University, Bangladesh, Dhaka 1229, Bangladesh

\begin{abstract}
Dye removal from textile wastewater has been a big challenge over the last decades. The effectiveness of adsorption for dyes removal from wastewater has made it an ideal alternative to other expensive treatment methods. This study inspects the possible use of chitin for the removal of dye from textile wastewater. Chitin was prepared from shrimp shell by a chemical process involving demineralization, de proteinization and decolorization. Prepared chitin was characterized by FTIR spectral analysis. The effects of various conditions such as adsorbent dose, $\mathrm{pH}$ and contact time were studied for this work. By using $1.5 \mathrm{~g}$ of chitin for $25 \mathrm{~mL}$ solution, the removal efficiency was achieved almost $96 \%$ at $\mathrm{p}^{\mathrm{H}}=5$ where the retention time was 60 minutes. The adsorbent behavior was studied on the basis of Langmuir isotherm model. The equilibrium adsorption data were fitted to the Langmuir isotherm equation. This study provides a cost effective and environment friendly dye removal process for textile wastewater treatment.
\end{abstract}

Keywords: Shrimp shell; Chitin; Wastewater; Dye removal efficiency; Biological Oxygen Demand (BOD); Chemical Oxygen Demand (COD); Fourier Transform Infrared Spectroscopy (FT-IR)

\section{Introduction}

Textile knit industry uses large amount of organic and inorganic chemicals as dyes that are directly or indirectly responsible for producing wastewater. The rate of wastewater disposals from the textile industries is reaching a warning level nowadays.

The discarding of colored wastes into the water bodies damages the environment and toxic to human and aquatic life. The wastewater contains very high concentration of $\mathrm{COD}$ and $\mathrm{BOD}$; and huge amount of suspended solids and other contaminants. Most sophisticated methods are required for treating wastewater in textile industries. Methods such as chemical, coagulation, flocculation, reverse osmosis, Nano-filtration, Ultra-filtration have been recommended. However these methods are very much complex and expensive. That is why these methods are not affordable to textiles industries in developing countries like Bangladesh.

Adsorption has gained supreme importance for environment protection by removing textile dyes from disposed water. Some of the adsorbents are effective in removing dyes and various pollutants, but some are not. That is why, new effective adsorbents are needed which should be cost effective, energy efficient, design flexible, biodegradable and available.

At present year different cost effective, commercially available adsorbents have been used for the removal of dyes from textile wastewater. However, the adsorption capacities of all the above adsorbents that are low cost and biodegradable are highly demanded. Chitin is a natural carbohydrate polymer found partially in the shells of crustaceans such as crab, shrimp, the cuticles of insects and the cells of fungi [1]. In Bangladesh shrimp are found from the coastal region of Satkhira, Khulna, Bagerhat and Cox's bazaar district. Chitin is considered as high efficient bio-adsorbent due to a high number of functional groups: $\mathrm{N}$-acetyl amine, amine and hydroxyl [1-3]. The chitin was prepared from shrimp shell that was used to carry out this research. The aim of this study was to exploit the potential of the prepared chitin as a bio - adsorbent for removing reactive dyes from textile wastewater with respect to amount of adsorbents, $\mathrm{pH}$ values, and contact time and applied Langmuir adsorption isotherm model to verify this study [4-10].

\section{Materials and Methods}

\section{Structure of chitin}

Chitin $\left(\mathrm{C}_{8} \mathrm{H}_{13} \mathrm{O}_{5} \mathrm{~N}\right)_{\mathrm{n}}$ is a long -chain organic polymer of a $\mathrm{N}$ - acetyl glucosamine that is a derivative of glucose. In terms of structure, chitin may be related to the polysaccharide cellulose and, in terms of role, to the protein keratin.

\section{Sample and adsorbents collection}

In this experiment, wastewater sample was collected from Sharp Knitting \& Dyeing Limited, Pagar, Tongi, Bangladesh. The sample contains mainly three types of reactive dyes as Deazol Black B EAN, Deafix Red ME 6BL and Firstfix Yellow 3RS. Chitin was used as an adsorbent for treating this wastewater. Chitin was prepared from shrimp shell that was collected from local fish market.

\section{Preparation of adsorbents}

The shrimp shells were washed with distilled water to remove dust and soluble impurities. After that the shrimp shells were dried in sun for longer period until completely dried. To obtain a uniform size product, the dried shells were ground through a centrifugal mortar. Then the shells were demineralized with $5 \%$ hydrochloric acid at ambient temperature with a solid to solvent ration of 1:14 (w/v) for 24 hours. The Demineralized shells were deproteinized with $5 \% \mathrm{NaOH}$ solution for 24 hours at $400^{\circ} \mathrm{C}$ temperature with solid to solvent ratio $1: 14$ $(w / v)$. Samples were then washed with distilled water \& decolorized with acetone. The samples were dried until the powder was crispy. The Resultant product was chitin [11-14].

*Corresponding author: Rahman FBA, School of Environmental Science and Management, Independent University, Bangladesh, Dhaka 1229, Bangladesh; Tel: +886939910932; E-mail: frahman033@icloud.com

Received August 06, 2016; Accepted August 08, 2016; Published August 15, 2016

Citation: Rahman FBA, Akter M (2016) Removal of Dyes Form Textile Wastewater by Adsorption using Shrimp Shell. Int J Waste Resour 6: 244. doi: 10.4172/22525211.1000244

Copyright: (c) 2016 Rahman FBA, et al. This is an open-access article distributed under the terms of the Creative Commons Attribution License, which permits unrestricted use, distribution, and reproduction in any medium, provided the original author and source are credited. 


\section{Preparation of standard solution}

$1 \mathrm{~L}$ of stock solution of Deazol Black B EAN reactive dye was prepared by dissolving a mixture of $0.1 \mathrm{~g}$ of dye in a volumetric flask followed by dilution up to the mark addition of de-ionized water. Prepared standard solution was used for the study of adsorption isotherm.

\section{Procedures}

Batch adsorption experiment was conducted by stirring a series of glass bottles containing $25 \mathrm{~mL}$ sample wastewater with different adsorbent amount $(0.5,1.0,1.5,2.0$ and $2.5 \mathrm{~g})$ for different time intervals $(30,60,90,120$ minutes $)$ at room temperature. The help of magnetic stirrer did the stirring. The stirring proceeded for 2 hours until the equilibrium reached. After which the mixture was left to settle for 3 hours. Then the solution was filtered with the help of filter paper. The filtrate's absorbance was determined by using US-VIS spectrometer at adjusted $\lambda_{\max }$. The followed adsorption experiment carried out.

Experiment 1: The effect of contact time: In this eperiment various effects of contact time between adsorbate and adsorbent were studied. The range of contact time was 30 to 120 minutes at $\mathrm{p}^{\mathrm{H}}=7$ and $2 \mathrm{~g}$ of adsorbent used for making $25 \mathrm{~mL}$ solution.

Experiment 2: The Effect of $\mathrm{p}^{\mathrm{H}}$ : $25 \mathrm{~mL}$ of solution was made using $1.5 \mathrm{~g}$ of adsorbent. The optimum contact time between adsorbate and adsorbent was 90 minutes. The $\mathrm{pH}$ was varied from 5 to $9 . \mathrm{p}^{\mathrm{H}}$ was adjusted using acetic acid and $\mathrm{NaOH}$.

Experiment 3: The effect of amount of adsorbent: This experiment was the observation of effects of adsorbent amount in waste removal. The range of adsorbent amount was $0.5 \mathrm{~g}$ to $2 \mathrm{~g}$ for $25 \mathrm{~mL}$ of solution. The optimum time for contact was 90 minutes at $\mathrm{p}^{\mathrm{H}}$ value 7 .

Experiment 4: Adsorption Isotherm for pure reactive dye onto shrimp shell: This experiment studied Langmuir adsorption isotherm onto the chitin of shrimp shell. A suitable condition was set that found from previous experiments to carry out this experiment.

\section{Results and Discussion}

\section{Effects of amount of adsorbent}

Figure 1 shows the percentage removal of waste from textile wastewater sample at $\mathrm{p}^{\mathrm{H}}=7$ for adsorbent dosage from $0.5 \mathrm{~g}$ to $2.5 \mathrm{~g}$. This experiment was carried out at room temperature and the contact time was 90 minutes. The result explained that the waste removal percentage was very low at beginning. Then percentage increased with increasing amount of dosage. This happened because initially the active site of adsorbent could not effectively contact with adsorbate. When the adsorbent amount was higher, the active portion was available for removing almost all the waste from sample wastewater. And the figure shows that the optimum amount of dose of chitin is $2 \mathrm{~g}$ at which maximum amount of dyes were removed. The maximum removal percentage is almost $96-97 \%$. Above $2 \mathrm{~g}$ of chitin dose, the proper contact did not happened, so the removal percentage decreased [15-20].

\section{Effects of dye-adsorbent contact time}

The dye removal percentage from sample wastewater with contact time between adsorbate and adsorbent is shown in Figure 2. The range of observed contact time was 30.120 minutes with the increment of 30 minutes. The experiment was carried out for optimum adsorbent dosage of $2 \mathrm{~g}$ at room temperature. The optimum $\mathrm{p}^{\mathrm{H}}$ of sample wastewater was 7 . The result revealed that the rate of dye removal

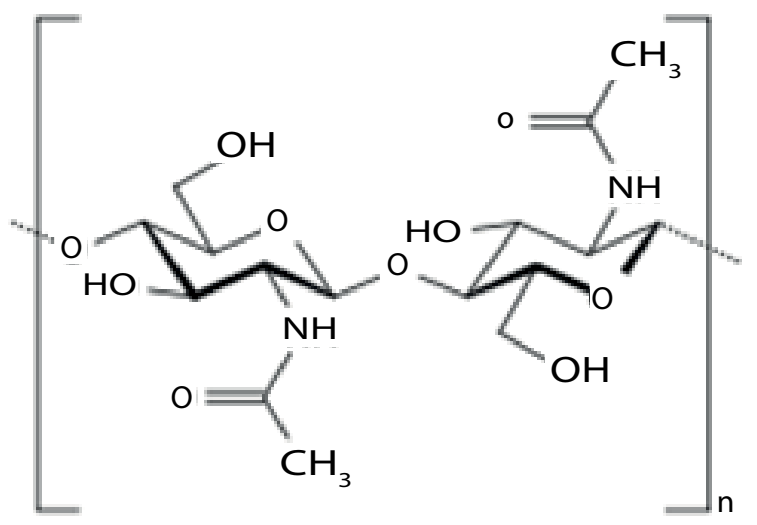

Figure 1: Structure of shrimp shell chitin.

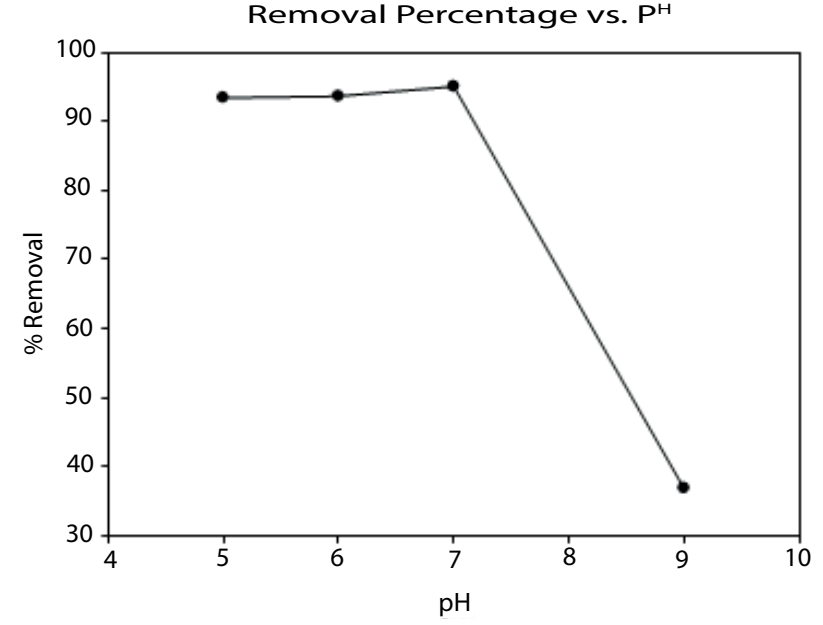

Figure 2: Effect of shrimp shell chitin dosage on the removal of dyes by adsorption onto shrimp shell. (Initial concentration: $1.5 \mathrm{~g} / 25 \mathrm{~mL} ; \mathrm{pH}$ value: 7 ; and contact time: 90 minutes).

percentage was very at the beginning of the experiment due to improper contact of adsorbent with dye in wastewater. Further, as contact time increased, the dye removal percentage also increased. For contact time 60 minutes the removal percentage was found maximum and the value was almost $95 \%$. But after 60 minutes contact time the removal percentage was decreased with time increased [21,22].

\section{Effects of $\mathbf{p}^{\mathrm{H}}$}

The $\mathrm{pH}$ value of the solution is an important parameter for the adsorption processes, and the initial $\mathrm{pH}$ value of the solution has significant influence compared to than the final $\mathrm{p}^{\mathrm{H}}$. To study the effect of $\mathrm{p}^{\mathrm{H}}$ on dyes adsorption, the experiment was carried out at $1.5 \mathrm{~g} / 25 \mathrm{~mL}$ at room temperature. In general, the initial $\mathrm{p}^{\mathrm{H}}$ value may enhance or depress the uptake. This is attributed to the change of adsorbent surface with the change of $\mathrm{p}^{\mathrm{H}}$ value. Figure 3 shows the relationship between $\mathrm{p}^{\mathrm{H}}$ values and percentage removal of dyes from wastewater sample. The value of $\mathrm{p}^{\mathrm{H}}$ varied from 5 to 9 . The optimum dose amount was $2 \mathrm{~g}$ and contact time was 60 minutes. The result revealed that the rate of percent removal of dyes from wastewater sample was $93 \%$ at beginning. Further, the increasing the value of $\mathrm{p}^{\mathrm{H}}$ of sample the removal percentage also 


\section{Removal Percentage vs. Contact Time}

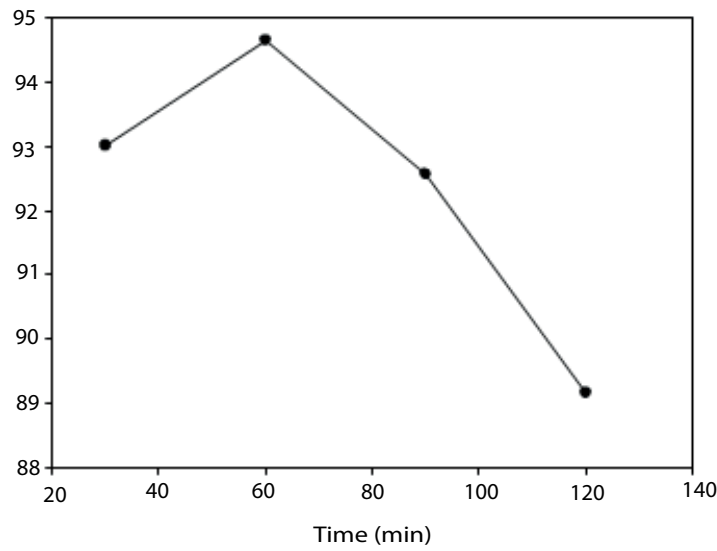

Figure 3: Effect of contact time on the removal of dyes by adsorption onto shrimp shell chitin. Initial concentration: $6 \mathrm{~g} / \mathrm{mL}$, Amount of chitin peel: 1.5 $\mathrm{g}$ and $\mathrm{pH}$ value: 7

increased very slightly. However, for $\mathrm{p}^{\mathrm{H}}$ above 7 the removal percentage was decreased very rapidly for improper contact of adsorbent [23-26].

\section{Adsorption}

The purpose of the adsorption isotherms is to relate the adsorbent concentration in the bulk solution and the adsorbed amount at the interface. The equilibrium isotherms in this study have been described in terms of Langmuir isotherm model. This adsorption model was plotted to study the removal capacity of materials. The Langmuir isotherm is an empirical equation assuming that the adsorption process take places as homogeneous sites, all sites are equivalent and there are no interactions between adsorbate molecule and adjacent sites. The adsorption data were analyzed according to the linear form of the Langmuir isotherm equation. A linear form of the Langmuir Isotherm equation is generally expressed as follows, Where $C_{e}$ represents the equilibrium dye concentration in solution $(\mathrm{mg} / \mathrm{L})$, qe is the adsorption capacities (amount of dye adsorbed per weight of adsorbent, $(\mathrm{mg} / \mathrm{g}$ ) $\mathrm{q}_{\mathrm{m}}$ and $\mathrm{K}_{\mathrm{a}}$ are Langmuir constant that can be determined from above Langmuir linear equitation. This adsorption experiment was carried out for only Deazol Black B EAN reactive dyes. The absorbance of the clear solution was measured spectrophotometrically at maximum wavelength $601 \mathrm{~nm}$.

Figure 4 also showed that adsorption of the Deazol Black B EAN dye fits well to angmuir isotherm model with the correlation coefficient (R2) of 0.997 , supporting monolayer converge of the adsorbate on the surface of the adsorbent. The results found from Langmuir isotherm model are illustrated by Table 1 .

The plot of $1 / q_{e}$ versus $1 / C_{e}$ showed that adsorption follow Langmuir isotherm model as illustrated in Figure 5. This figure employed to evaluate the value of $\mathrm{q}_{\mathrm{m}}$ and $\mathrm{K}_{\mathrm{a}}$ from the slope and intersect of the plot that presented in Table 1 .

\section{Characterization of prepared chitin by FTIR spectroscopy}

The FT-IR spectrum of chitin prepared from shrimp shells is showed in Figure 6. The FT-IR spectrum presented a broad adsorption bond at around $3451 \mathrm{~cm}^{-1}$ corresponding to the vibrational stretching of hydrogen bonded $\mathrm{N}-\mathrm{H}$ and $\mathrm{O}-\mathrm{H}$. The spectrum also shared characteristics peaks of amide I at $1657 \mathrm{~cm}^{-1}$ ( $\mathrm{C}=\mathrm{O}$ stretching), amide

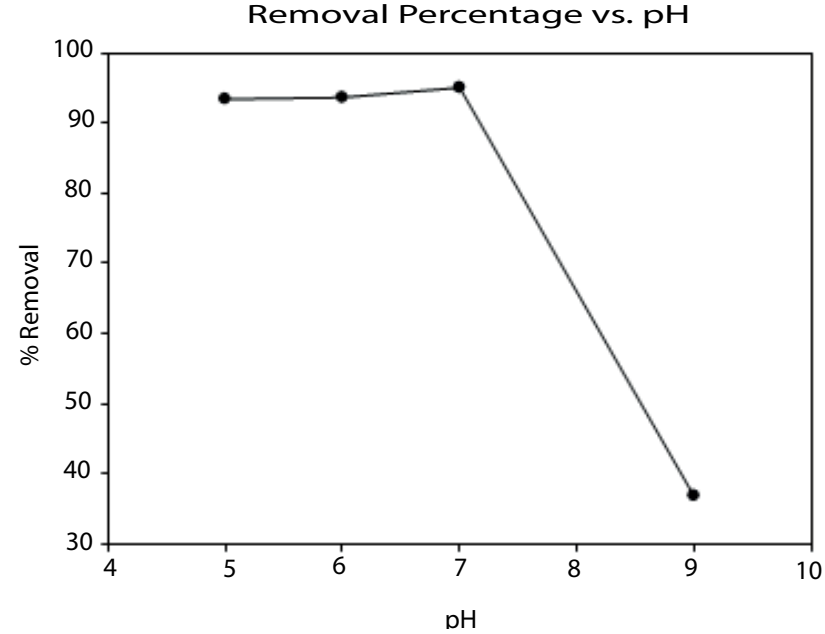

Figure 4: Effect of $\mathrm{pH}$ on the removal of dyes by adsorption onto shrimp shell chitin. Initial concentration: $6 \mathrm{~g} / \mathrm{L}$, amount of adsorbent: $1.5 \mathrm{~g}$ and contact time: 90 minutes.

\begin{tabular}{|c|c|c|c|c|}
\hline \multirow{2}{*}{ Adsorbent } & Dye & \multicolumn{3}{|c|}{ Langmuirisotherm equation } \\
\cline { 3 - 5 } & $\mathbf{R}^{\mathbf{2}}$ & $\begin{array}{c}\mathbf{q m} \\
\mathbf{( m g / L )}\end{array}$ & $\mathbf{K a}$ \\
\hline $\begin{array}{c}\text { Banana } \\
\text { peel }\end{array}$ & $\begin{array}{c}\text { Deazol Black } \\
\text { B EAN }\end{array}$ & 0.997 & 3.583 & 0.939 \\
\hline
\end{tabular}

Table 1: Parameters obtained from correlation of Langmuir adsorption isotherm.

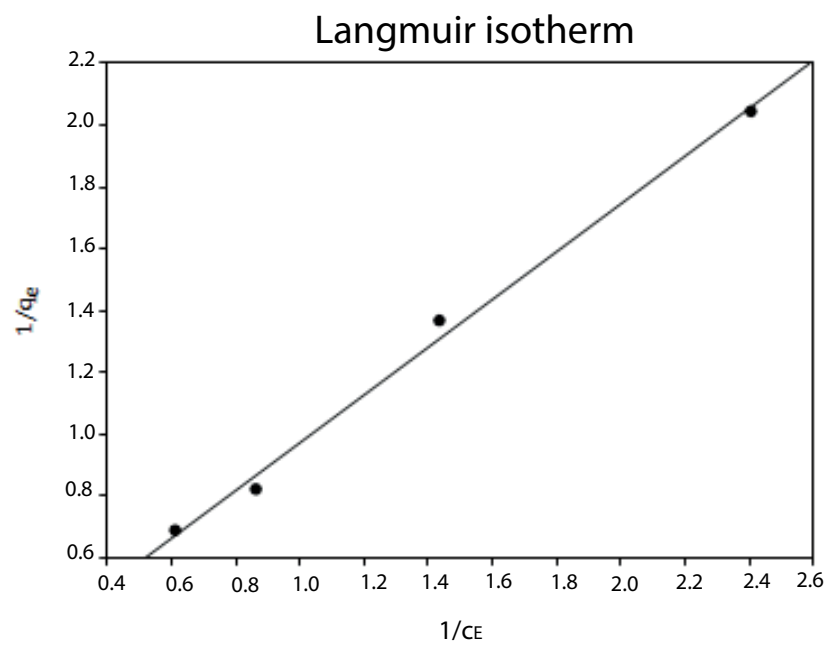

Figure 5: Langmuir isotherm for Deazol Black B EAN reactive dye onto banana peel (initial concentration: 20--60 mg/L; time: 180 minutes, $\mathrm{pH}$ : 6.5--7; room temperature).

II at $1566 \mathrm{~cm}^{-1}(\mathrm{~N}-\mathrm{H}$ in plane deformation coupled with $\mathrm{O}-\mathrm{H}$ in the plane deformation) and $\mathrm{CH}_{2}$ wagging coupled with $\mathrm{O}-\mathrm{H}$ in the plane deformation at $1322 \mathrm{~cm}^{-1}$. The peaks observed at around 2932 and 2891 $\mathrm{cm}$ were assigned to $\mathrm{sp} 3 \mathrm{C}-\mathrm{H}$ stretching (symmetric and asymmetric). The band at $1381 \mathrm{~cm}^{-1}$ corresponded to $\mathrm{C}-\mathrm{H}$ bending and symmetric $\mathrm{CH}_{3}$ deformation, while the bond at $1426 \mathrm{~cm}^{-1}$ was due to $\mathrm{CH}_{2}$ bending and $\mathrm{CH}_{3}$ deformation. The bend observed at $1160 \mathrm{~cm}-1$ was indicated 


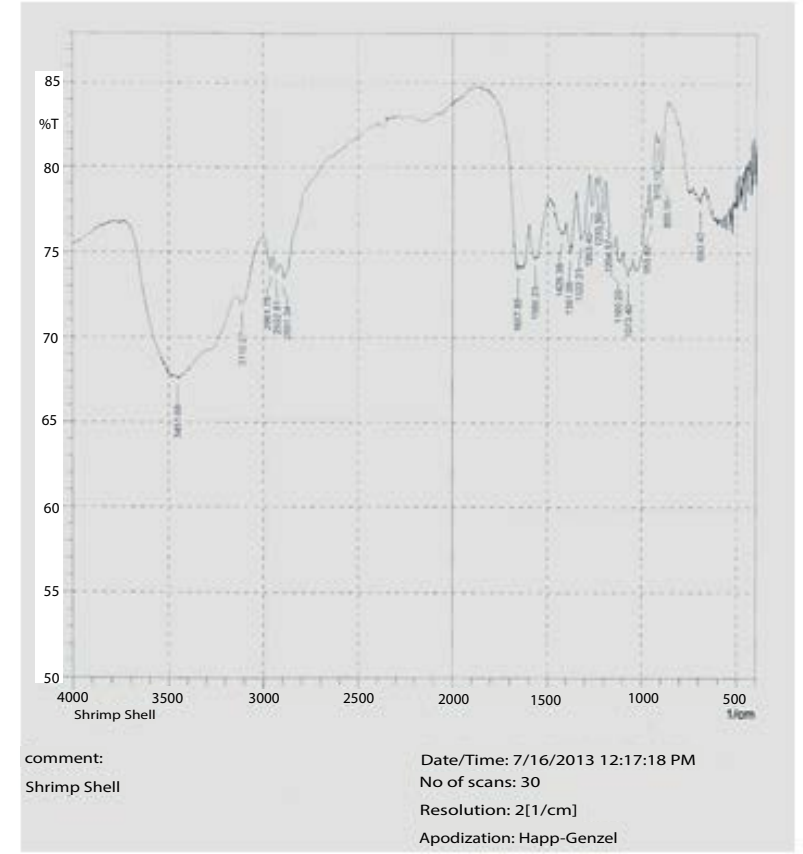

Figure 6: FT-IR spectrum for prepared chitin

a bridged oxygen stretching (C-O-C linkage of ring). The $\mathrm{C}=\mathrm{O}$ Stretching vibration bonds were observed at 1073 and $953 \mathrm{~cm}^{-1}$. The characteristics peak for $\mathrm{CH}$ deformation of the $\beta$-glycosidic bond was observed at $896 \mathrm{~cm}^{-1}$.

\section{Conclusion}

In this work the removal of reactive dyes from textile wastewater by batch adsorption using shrimp shell (chitin) was investigated. This study monitored the ability of chitin for removing dyes from wastewater with various adsorbent dose, contact time and $\mathrm{p}^{\mathrm{H}}$. The maximum percentage of dyes reduction was obtained at an optimum dose of $2 \mathrm{~g}$, an optimum contact time of 60 minutes and an optimum $\mathrm{p}^{\mathrm{H}}$ of 7 . Shrimp shell chitin has been found to be comparatively better adsorbent because it can remove almost $96-97 \%$ of dyes from the wastewater. Finally, the result of adsorption study, it is concluded that shrimp shell chitin can be used as a coagulant for reactive dyes from textile wastewater because of its higher adsorptive capacity, cost effectiveness, environment friendly behavior and availability in nature [27-30].

\section{Acknowledgement}

At first, we hereby express our utmost gratitude to the almighty Allah for successful completion of this research. I am deeply indebted to my honorable supervisor Dr. M. Zainal Abedin, Professor, Department of environment management, Independent University, Bangladesh who provided his encouraging guidance, thoughtful suggestion which were essential ingredients to complete this work. It was his constructive comments which made me able to bring this work to a successful completion. I also wish to thank all the faculty members for their help during the project.

\section{References}

1. Rinaudo M (2006) Chitin and chitosan: Properties and applications. Progress in Polymer Science 31: 603-632.

2. McKay G, Blair HS, Gardner JR (1984) The adsorption of dyes onto chitin in fixed bed columns and batch adsorbers. J Appl Polymer Sci 29: 1499-1514.
3. Akkaya G, Uzun I, Guzel F (2009) Adsorption of some highly toxic dyestuffs from aqueous solution by chitin and its synthesized derivatives. Desalination 249: $1115-1123$

4. Begum HA, Mondal AK, Muslim T (2012) Adsorptive Removal of Reactive Black 5 from Aqueous Solution using Chitin Prepared from Shrimp Shells. Bangladesh Pharmaceutical Journal 15: 145-152.

5. Akkaya G, Uzun I, Güzel F (2007) Kinetics of the adsorption of reactive dyes by chitin. Dyes and Pigments 73: 168-177.

6. Saha TK, Bhoumik NC, Karmaker S, Ahmed MG, Ichikawa H (2011) Adsorption characteristics of reactive black 5 from aqueous solution onto chitosan. CLEAN - Soil, Air, Water 39: 984-993.

7. Freundlich $\mathrm{HZ}$ (1906) Over the adsorption in solution. J Phys Chem 57A: 385-470.

8. Filipkowska U (2007) Adsorption and Desorption Efficiency of Black 8 and Black 5 onto Chitin and Chitosan.

9. Chiou MS, Li HY (2003) Adsorption behavior of reactive dye in aqueous solution on chemical cross. linked chitosan beads. Chemosphere 50: 10951105.

10. Khan TA, Singh VV, Kumar D (2004) Removal of some basic dye from artificial textile waste water by adsorption on Akash Kinari coal. J Sci Ind Res 63: 355-364.

11. Lima IS, Airoldi CA (2004) Thermodynamic investigation on chitosan divalent cation interactions. Thermochimica Acta 4: 133-139.

12. Maruca R, Jo Sunder B, Wightman JP (1982) Interaction of heavy metals with chitin \& chitosan. III. Chromium. J Appl Pol Sci 27: 4827-4837.

13. Wanjun T, Cuxin W, Donghua C (2005) Kinetic studies on the pyrolysis of chitin and Chitosan. Pol Deg Stab 87: 389-394.

14. Dolphen R, Sakkayawong N, Thiravetyan P, Nakbanpote W (2007) Adsorption of Reactive Red 141 from wastewater onto modified chitin. J Haz Mater 145: 250-255.

15. Shirsath DS, Shrivastava VS (2012) Removal of Hazardous dye Ponceau-S by using chitin, An organic bioadsorbent. Afr J Environ Sci Technol 6: 115-124.

16. Maruca R, Jo Sunder B, Wightman JP (1982) Interaction of heavy metals with chitin \& chitosan III Chromium. J Appl Pol Sci 27: 4827-4837.

17. Attia AA, Girgis BS, Khedr SA (2003) Capacity of activated carbon derived from pistachio shells by $\mathrm{H} 3 \mathrm{PO} 4$ in the removal of dyes and phenolics. J Chem Technol Biotechnol 78: 611-619.

18. Dursun AY (2003) The effect of $\mathrm{pH}$ on the equilibrium of heavy metal bisorption by Aspergillus miger. Fresenius Environ Bull 12: 1315-1322.

19. Kim SK, Rajapakse N (2005) Enzymatic roduction and biological activities of chitosan oligosaccharides (COS): A review. Carboh Pol 62: 357-368.

20. Marthur NK, Narang CK (1990) Chitin and Chitosan, versatile polysaccharides from marine animals. J Chem Ed 67: 938-942.

21. Dutta PK, Ravikumar MNV, Dutta J (2002) Chitin and chitosan for versatile applications. J Macromol Sci Pol Rev 3: 307-354.

22. Majeti NV, Kumar R (2000) A review of chitin and chitosan applications. React Funct Pol 46: 1-27.

23. Blackburn R (2004) Natural polysaccharides \& their interactions with dye molecules: applications in effluent treatment. Environmen Sci Technol 38 4905-4909.

24. Sugimoto $M$, Morimoto $M$, Sashiwa $H$, Saimoto $H$, Shigemasa $Y$ (1998) Preparation and characterization of water soluble chitin and chitosan derivatives. Carboh Pol 36: 49-59.

25. Barka N, Abdennouri M, Makhfouk MEL (2011) Removal of Methylene Blue and Eriochrome Black $\mathrm{T}$ from aqueous solutions by biosorption on Scolymus hispanicus L.: Kinetics, equilibrium and thermodynamics. J Taiwan Inst Chem Eng 42: 320-326.

26. Tang $H$, Zhou $W$, Zhang $L$ (2012) Adsorption isotherms and kinetic studies of malachite green on chitin hydrogels. J Hazard Mater.

27. Brunauer S, Emmett PH, Teller E (1938) Adsorption of gases in multimolecular layers. J Am Chem Soc 60: 309-319. 
Citation: Rahman FBA, Akter M (2016) Removal of Dyes Form Textile Wastewater by Adsorption using Shrimp Shell. Int J Waste Resour 6: 244. doi: $10.4172 / 2252-5211.1000244$

Page 5 of 5

28. Mall ID, Srivastava VC, Kumar GVA, Mishra IM (2006) Characterization and utilization of mesoporous fertilizer plant waste carbon for adsorptive removal of dyes from aqueous solution. Col Surf A: Physicochem Eng Aspect 323: 47-53.

29. Kyzas GZ, Lazaridis NK (2009) Reactive and basic dye removal by sorption onto chitosan derivatives. J Colloid Interface Sci 331: 32.39.
30. Samiey B, Toosi A (2010) Kinetic of malachite green fading in alchol -water binery mixtures. Int $\mathrm{J}$ Chem Kinetic 42: 508-518. 